\title{
Effectiveness evaluation of the school- based drug prevention program \#Tamojunto2.0: protocol of a cluster randomized controlled trial
}

Zila M. Sanchez ${ }^{1 *}$ (D, Juliana Y. Valente ${ }^{1}$, Ana Paula Dias Pereira ${ }^{1}$, Hugo Cogo-Moreira ${ }^{2}$, Márcia H. S. Melo ${ }^{3}$, Sheila C. Caetano ${ }^{2}$ and Jair J. Mari ${ }^{2}$

\begin{abstract}
Background: The European school-based drug addiction prevention program Unplugged was adapted to the Brazilian context by the Ministry of Health and renamed \#Tamojunto. Its first implementations, in the form of a public policy in Brazil, showed contradictory and different effects from those observed in Europe. Adaptations were made to \#Tamojunto in 2018 to reintroduce the essential content of the original program.

Methods: A parallel, two-arm, randomized controlled trial (RCT) will be conducted to evaluate the effectiveness of the new version of the school-based government program \#Tamojunto2.0 for the prevention of drug use among 8th grade middle school students from 70 public schools in three Brazilian cities, totaling approximately 6.300 participating students distributed in 210 classes. For intervention, the experimental group will receive the 12 lessons of the \#Tamojunto2.0 program under the supervision of a Brazilian Ministry of Health team. The control group will not receive any intervention. Information will be collected from the students at three time points: preintervention and 9 and 18 months postintervention. Multilevel analyses will be performed using the Gllamm Stata program to assess simultaneous differences in prevalence, in time and among groups for the outcomes of interest. Structural equation modeling will be used to evaluate the effectiveness of the intervention in changing the behavioral patterns of the adolescents through latent transition analysis. The effect of the mediators involved in the program effectiveness outcomes will also be analyzed. The program doses applied in all classes of the intervention group will be collected using a form completed by the teacher at the end of each lesson, indicating the activities taught and not taught in each lesson.
\end{abstract}

Discussion: This study will show whether the \#Tamojunto2.0 program can be expanded as a public policy for all schools with the aim of preventing drug use among Brazilian students.

Trial registration: Brazilian Clinical Trials Registry (RBR-8cnkwq) under the name "Avaliação do Efeito do Programa de Prevenção Escolar ao Uso de Drogas \#Tamojunto2.0, Versão 2018", on August 30th, 2018 (http://www. ensaiosclinicos.gov.br/rg/RBR-8cnkwq/).

Keywords: Randomized controlled trial, Prevention programs, Drug use, Protocol study

\footnotetext{
* Correspondence: zila.sanchez@gmail.com

${ }^{1}$ Department of Preventive Medicine, Universidade Federal de São Paulo, Rua

Botucatu, 740, São Paulo 04023-062, Brazil

Full list of author information is available at the end of the article
}

(c) The Author(s). 2019 Open Access This article is distributed under the terms of the Creative Commons Attribution 4.0 International License (http://creativecommons.org/licenses/by/4.0/), which permits unrestricted use, distribution, and reproduction in any medium, provided you give appropriate credit to the original author(s) and the source, provide a link to the Creative Commons license, and indicate if changes were made. The Creative Commons Public Domain Dedication waiver (http://creativecommons.org/publicdomain/zero/1.0/) applies to the data made available in this article, unless otherwise stated. 


\section{Background}

The abuse of alcohol and other drugs is currently a major public health issue [1], and adolescent substance use is considered one of the main risk behaviors for the development of subsequent problems, such as dependence [2], cognitive impairment [3] and psychiatric disorders [4]. In Brazil, 55.5\% of students between the ages of 13 and 15 have reported the consumption of alcoholic beverages, and 9\% have reported illicit drug use [5].

The high prevalence of drug use in adolescence and the early age of onset of this behavior show the need for prevention programs in these age groups $[6,7]$. Schoolbased prevention programs have been implemented worldwide to reduce or delay the onset of alcohol and other drug use among adolescents [8]. Among the prevention models that have been shown to be effective are those that consider the social influences on the initiation of consumption, working towards reducing the risk factors and increasing the protective factors [9-11].

In 2013, the Brazilian Ministry of Health (BMH), in partnership with the United Nations Office on Drugs and Crime (UNODC), carried out a cross-cultural adaptation of Unplugged-a school-based program for substance use prevention, which was called \#Tamojunto in Brazil [12]. The program is based on the "Comprehensive Social Influence Model" [13], whose approach attempts to build specific skills in adolescents that enable them to manage social influences, deconstructing normative beliefs, and is based on reflections on the contexts of drug use and knowledge about drugs and their health effects. When evaluated in European countries, Unplugged produced significant reductions in reports of episodes of drunkenness, frequent use of marijuana [14], tobacco use and use of any drug [15].

After translation into Brazilian Portuguese and cultural adaptation, in 2014 and 2015, the first Brazilian study on the effectiveness of \#Tamojunto was conducted through a randomized controlled trial in six cities involving a sample of 6391 students from 72 public schools. The short-term (nine month follow-up) [16] and long-term (21 month follow-up) results showed a negative effect on alcohol initiation [17]. The adolescents in the intervention group had a 30\% higher risk (95\%CI 1.13-1.49) at 9 months and a $13 \%$ higher risk (95\%CI 1.01-1.27) [16] at 21 months for first alcohol use compared to those in the control group [17]. The main hypothesis to explain these iatrogenic results suggests inadequate cultural adaptations for the alcohol components. The adaptation did not include the original components that reinforced the nonuse of alcohol and emphasized only the prevention components aimed at avoiding alcohol intoxication, with an emphasis on harm reduction [18].

Considering the negative results of \#Tamojunto, in 2018, there was a significant change in the activities and content of the lessons that addressed alcohol and its effects. This new adaptation of the material aims to reintroduce the central elements of the European Unplugged program [14] and now requires a new evaluation of its results in the Brazilian population before expanding it into a formal public policy. This new adaptation also comes with a change in its visual identity, and the name has been changed to \#Tamojunto2.0.

It is important to emphasize that drug prevention programs based on a theoretical psychosocial framework usually have protective effects on other risk behaviors of adolescents [11], as they act on risk and protective factors shared by several negative health outcomes, such as violence and psychiatric disorders [19-21]. In this sense, it is also important to investigate the effects of the \#Tamojunto2.0 program on secondary outcomes, such as violence and different psychiatric symptoms, in Brazil.

\section{Methods \\ Aims}

The main objective of the study is to evaluate the effectiveness of the school-based program \#Tamojunto2.0 at 9 and 18 months of follow-up in the prevention of drug use (alcohol, tobacco, inhalants, marijuana, cocaine, crack and amphetamines) and binge drinking among Brazilian students. Our main hypothesis is that the \#Tamojunto2.0 program will delay the first use of these drugs and will decrease the prevalence of use among students who participate in the intervention compared to the students in the control group.

The second objective of this study is to evaluate the effectiveness of the program at 9 and 18 months of followup in the prevention of school violence and psychiatric symptoms (depression, anxiety, attention-deficit/hyperactivity disorder and eating disorders) among Brazilian students. Our second hypothesis is that the \#Tamojunto2.0 program will reduce the prevalence and incidence of secondary outcomes among students participating in the intervention compared to the students in the control group.

The third objective of the study is to evaluate the mediating effect of the skills taught by the program (decision-making skills, refusal skills, knowledge about drugs and beliefs about drugs) in reducing primary outcomes (alcohol, tobacco, marijuana, inhalant, cocaine, crack and amphetamine use and binge drinking) and secondary outcomes (reports of school violence and psychiatric symptoms), comparing the control and intervention groups at three different time points $(0,9$ and 18 months). Our third hypothesis is that the improvement in the skills taught by the program will mediate the program's effect on reducing the primary and secondary outcomes, as described by a logical model. 
Finally, the fourth objective of the present study is to evaluate the program implementation fidelity to identify possible changes in the original content and to measure if the dose of the program offered to the students influences the effects of the program. Our fourth hypothesis is that the greater the dose of the program offered to the students and the smaller the changes to the original content are, the greater the effect of the program in the prevention of the proposed outcomes will be.

\section{Study design}

A randomized controlled trial with two parallel groups (intervention and control) will be conducted to evaluate the effectiveness of the program for adolescents enrolled in 8th grade middle school in 70 public schools in three Brazilian cities, totaling approximately 6300 students distributed in 210 groups. Randomization will be conducted at the school level. Schools randomly selected to be part of the intervention group will offer the 12 lesson \#Tamojunto2.0 program in the year 2019. Schools in the control group will not offer prevention programs or activities in 2019. The selection of schools and the allocation to the control or intervention group will be performed by a simple random draw from the list of the National Institute for Educational Studies and Research 'Anísio Teixeira' (INEP), which includes all schools from each municipality.

The baseline data (T1) will be collected two weeks before implementation of the program in February/March 2019, and the follow-up data will be collected at 9 months (T2) in November/December 2019 and at 18 months (T3), August/September 2020 after the initial data collection in August 2020. The data will be collected simultaneously for both groups. This protocol was prepared in accordance with SPIRIT 2013 [22], and the study will be conducted according to the CONSORT guidelines [23].

At the end of each lesson, all teachers in the experimental classes will complete a fidelity and dose form, stating which of the planned activities were or were not taught in the lesson and if the teacher made any changes. Figure 1 shows the study design flowchart.

\section{Participants}

Eighth-grade middle school students aged 12 to 14 years, enrolled in public schools from three Brazilian cities (Fortaleza, Eusébio - northeastern region - and São Paulo - southeastern region) will participate in the effectiveness evaluation of the program. The participating cities were recommended by the $\mathrm{BMH}$, based on the identification of the municipalities in which there was already collaboration and a partnership with the local government for the application of the \#Tamojunto2.0 program. In addition, the selected cities have large sociodemographic differences; the two cities in the northeast are poorer and less populous than São Paulo, which is the fifth most populous city and the tenth richest city in the world.

\section{Sample size calculation}

The PASS 15.0 software was used to calculate the sample sizes of the two intervention groups in a cluster randomized design [24]. A sample size of at least 3150 adolescents in the control group and 3150 in the intervention group, distributed among 35 clusters (schools) with at least 90 subjects in each arm, will reach a power of $82 \%$ in identifying a difference between groups of $2.5 \%$ for the outcome of binge drinking in the past month, with an initial prevalence of $10 \%$, a significance level of $5 \%$, and an intraclass correlation of 0.005 . Thus, it is necessary to ensure the inclusion of at least three 8th grade classes from each sampled school, with 35 schools in the intervention group and 35 in the control group. Therefore, 70 schools will be selected to ensure a minimum sample size of 6300 adolescents, considering possible losses to follow-up.

\section{Randomization}

Schools from each of the participating municipalities registered in the INEP's national registry of schools will be randomly selected. The schools must meet the following inclusion criteria: (a) a public school and (b) have at least three 8th grade classes. Thirty schools will be drawn in Fortaleza, 30 schools in São Paulo and 10 schools in Eusébio. Among the schools selected to participate in the study, a second random draw will define which schools will be included in the control group and which will be included in the experimental group, maintaining a ratio of 1:1 in the number of control and experimental schools in each municipality. After selecting the schools, a list with the names of the selected schools will be forwarded to each education department of the participating municipalities to request authorization for participation in the study. Due to the involvement of the government, all schools typically agree to participate, as occurred in a previous study [16].

\section{Instrument}

The instrument to be used for data collection in evaluating the program effectiveness was designed using instruments previously used in studies evaluating the effect of drug prevention programs both in Brazil [16, 25] and abroad [14]. One of the instruments used as a base was created by the EU-DAP (European Drug Addiction Prevention Trial) and used in a previous effectiveness evaluation of Unplugged [26]. In Brazil, this instrument has been translated and adapted into Portuguese [27], with some questions replaced by questions adopted from two 


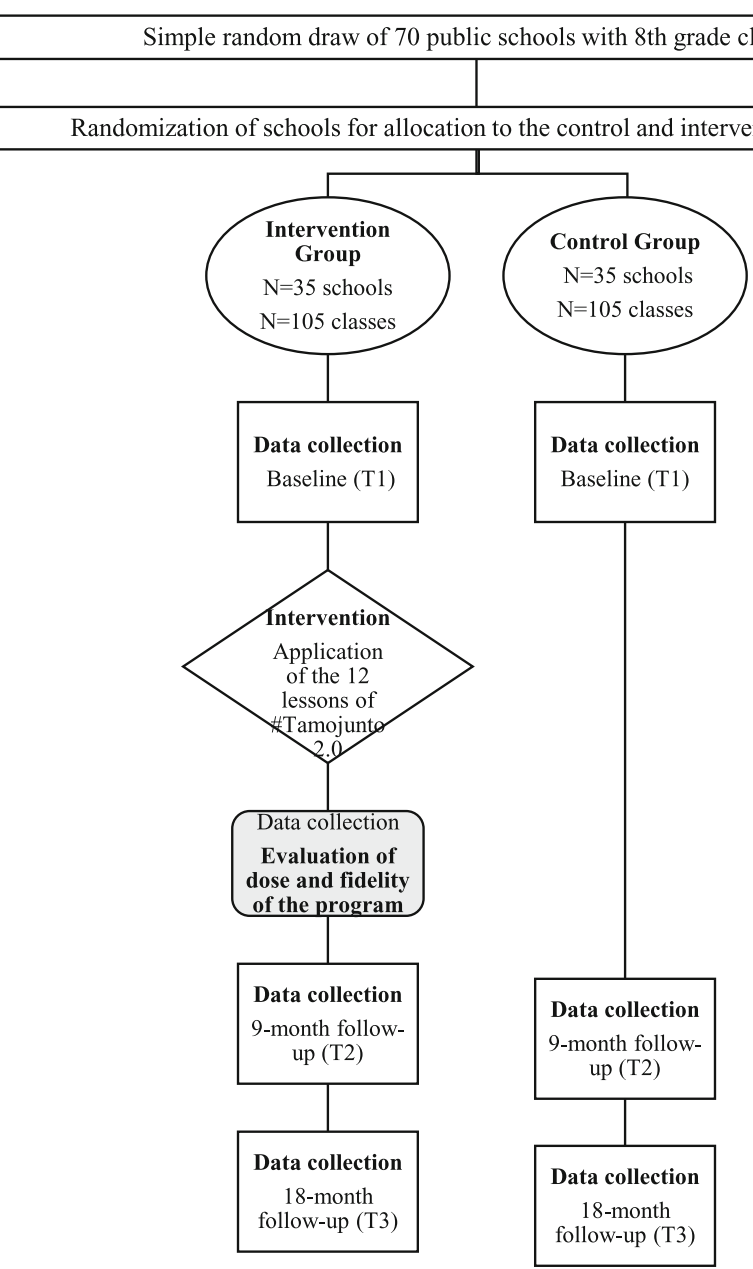

Fig. 1 Flowchart of the general design of the effectiveness evaluation of Tamojunto 2.0

questionnaires widely used in several studies among Brazilian students: the World Health Organization questionnaire used in the VI Brazilian Survey of Drug Use among Students [28] and the National Survey of School Health questionnaire used by the Ministry of Health [5]. Details of the instrument are presented in Table 1.

The form that evaluates dose and fidelity (Table 2), to be completed at the end of each lesson by the experimental group teachers, was prepared based on the EUDAP instrument [29].

To match the questionnaires across the evaluation time points, students will fill out a secret code on the first page of the questionnaire that involves generating letters and numbers from personal information. In this way, the codes can only be decoded by the students themselves. The codes allow the researchers to match individual questionnaires from different evaluation time points while providing the anonymity and confidentiality essential for a study of illicit behavior [36]. The databases of the two evaluation time points will be integrated by matching the secret codes using the Levenshtein algorithm, which can identify similarities between a set of characteristics [37].

\section{Primary outcomes}

The primary outcomes will be assessed through dichotomous questions about use in the last 30 days (yes/no), in the last 12 months (yes/no), and prior to the study period (incidence $=$ new cases) of the drugs alcohol, tobacco, marijuana, inhalants, cocaine, crack and amphetamines and binge drinking.

\section{Secondary outcomes}

The following will be evaluated as secondary outcomes: 1. episodes of violence in school measured through two scales for evaluating bullying suffered and bullying perpetrated in the last 30 days [30] and 2. current psychiatric symptoms (anxiety, depression, hyperactivity and current behavior and symptoms of eating disorders) [31, 32] [33]. 
Table 1 Details of the instrument to be applied among the students at the evaluation time points

\begin{tabular}{|c|c|c|c|}
\hline Variable & Main Use * & Source & Scale \\
\hline $\begin{array}{l}\text { Drug use in lifetime (first use, } \\
\text { incidence and prevalence), past } \\
\text { year and past month (prevalence) }\end{array}$ & $\begin{array}{l}\text { Primary outcomes (alcohol, tobacco, } \\
\text { marijuana, inhalant, cocaine, crack and } \\
\text { amphetamine use and binge drinking) }\end{array}$ & CEBRID [28] & 22 dichotomous questions \\
\hline Socioeconomic class & Confounder & ABEP [35] & A scale with 15 items \\
\hline Demographic data & Confounders & CEBRID [28] & 2 questions (age and sex) \\
\hline Decision-making & Mediator & EUDAP [26] & A scale with 9 dichotomous items \\
\hline Positive and negative beliefs & Mediator & & $\begin{array}{l}\text { Two scales with } 11 \text { dichotomous items each (one } \\
\text { for alcohol and one for marijuana) }\end{array}$ \\
\hline Normative beliefs & Mediator & & $\begin{array}{l}\text { Two scales: a Likert scale with } 4 \text { items and a } \\
\text { dichotomous scale with } 11 \text { items }\end{array}$ \\
\hline Knowledge about drugs & Mediator & & A scale with six items \\
\hline Refusal skill & Mediator & & A scale with three items \\
\hline School violence & Secondary outcome & $\begin{array}{l}\text { Olweus Bully } \\
\text { Victim } \\
\text { Questionnaire } \\
\text { [30] }\end{array}$ & $\begin{array}{l}\text { Two scales: a scale to measure violence } \\
\text { perpetrated with eight dichotomous items each } \\
\text { and a scale to measure violence suffered with } \\
\text { seven dichotomous items each }\end{array}$ \\
\hline Psychiatric symptoms & Secondary outcome & $\begin{array}{l}\text { Strengths and } \\
\text { Difficulties } \\
\text { Questionnaire } \\
\text { [31] }\end{array}$ & A scale with 25 dichotomous items \\
\hline Eating disorders & Secondary outcome & SCOFF [33] & A scale with 5 dichotomous items \\
\hline
\end{tabular}

\section{Mediators}

As mediators of program effectiveness, the following will be evaluated: 1 . normative beliefs; 2 . positive beliefs and negative beliefs about alcohol and marijuana use; 3 . knowledge about drugs; 4 . decision-making skills; and 5. refusal skills [34]. The scales for each mediator are described in Table 1.

In addition to the modules covering primary outcomes, secondary outcomes and mediators, the questionnaire also has a module on sociodemographic data. The socioeconomic class will be evaluated through the ABEP (Brazilian Market Research Association) scale [35] (Table 1).

\section{Intervention}

In each of the experimental schools, all 8th grade students will receive the program \#Tamojunto2.0, and the school will assign one teacher per class to receive training on the program.

The \#Tamojunto2.0 program will be applied to students in the classroom by trained teachers. The 12 lessons, described in Table 3, use interactive methods and will be guided by student and teacher handbooks. On average, the lessons last $50 \mathrm{~min}$ each. The program consists of four lessons on attitudes and knowledge about drugs, four lessons on social and interpersonal skills, and four lessons on personal skills. Each lesson will have three to five activities addressing life skills [13, 38]. The teacher's handbook provides information about each lesson's procedures, objectives, required materials, activities to be followed and tips. Both handbooks are freely accessible and can be found in several languages at www.eudap.net.

In Brazil, the English materials were translated into Portuguese, with adaptation of idiomatic expressions and the substitution of information about heroin for information about crack, as well as changes in the lessons addressing alcohol use [28]. The new adaptation, created in 2018, removed the changes made to the alcohol use lessons during the years 2014 and 2015 and changed class 3 on alcohol back to its original form (i.e., the European model) to remove the possible iatrogenic cultural adaptations regarding alcohol use [16]. Therefore,

Table 2 Instrument for evaluating the \#Tamojunto2.0 program implementation dose and fidelity

\begin{tabular}{|c|c|c|c|}
\hline Instrument & Completion & Goals & Content \\
\hline $\begin{array}{l}\text { Forms for monitoring the } \\
\text { application of the } \\
\text { \#Tamojunto } 2.0 \text { lesson-by-lesson. } \\
\text { Teacher. }\end{array}$ & $\begin{array}{l}\text { To be completed after each } \\
\text { of the } 12 \text { program lessons by } \\
\text { the teachers who will } \\
\text { implement the program. }\end{array}$ & $\begin{array}{l}\text { Assess the dose of program activities } \\
\text { being provided by teachers to students } \\
\text { and whether the teacher is following } \\
\text { the original lesson plan of the program. }\end{array}$ & $\begin{array}{l}\text { - The teacher will complete the form at } \\
\text { the end of each class, reporting which of } \\
\text { the activities planned for that lesson (as } \\
\text { stated in the student and teacher } \\
\text { handbooks) were actually fully taught to } \\
\text { the students and whether any changes } \\
\text { were made to the lessons. }\end{array}$ \\
\hline
\end{tabular}


Table 3 Description of the 12 lessons in the \#Tamojunto 2.0 program, including their title, activities and goals

\begin{tabular}{|c|c|c|c|}
\hline Lesson & Title & Activities & Goals \\
\hline 1 & \#Tamojunto introduction & $\begin{array}{l}\text { - Presentation } \\
\text { - Group work: coexistence } \\
\text { contract management } \\
\text { - Homework }\end{array}$ & $\begin{array}{l}\text { Introduction to the program, establishment of rules for the lessons and reflection } \\
\text { on what is known about drugs }\end{array}$ \\
\hline 2 & Where do I belong? & $\begin{array}{l}\text { - Situation play } \\
\text { - Game discussion }\end{array}$ & Clarify the influences and expectations of the group \\
\hline 3 & $\begin{array}{l}\text { Choices: protective and risk } \\
\text { factors for alcohol use }\end{array}$ & $\begin{array}{l}\text { - Information on different } \\
\text { factors influencing drug use } \\
\text { - Discussion and work in } \\
\text { small groups }\end{array}$ & Information on different factors influencing drug use \\
\hline 4 & $\begin{array}{l}\text { What do you think reflects } \\
\text { reality? }\end{array}$ & $\begin{array}{l}\text { - Presentation } \\
\text { - General discussion } \\
\text { - Group work } \\
\text { - Game }\end{array}$ & $\begin{array}{l}\text { Encourage critical analysis of information, reflection on differences between } \\
\text { personal opinions and actual data, reassessment of norms }\end{array}$ \\
\hline 5 & $\begin{array}{l}\text { What we know and do not } \\
\text { know about smoking }\end{array}$ & $\begin{array}{l}\text { - Quiz } \\
\text { - General discussion } \\
\text { - Feedback } \\
\text { - Game }\end{array}$ & $\begin{array}{l}\text { Information on the effects of smoking, differentiation of expected vs. real effects } \\
\text { and short-term vs. long-term effects }\end{array}$ \\
\hline 6 & Express yourself & $\begin{array}{l}\text { - Game } \\
\text { - Discussion and plenary } \\
\text { - Group work }\end{array}$ & $\begin{array}{l}\text { Proper communication of emotions, distinction between verbal and nonverbal } \\
\text { communication }\end{array}$ \\
\hline 7 & $\begin{array}{l}\text { Manifest yourself in the } \\
\text { world and in your life }\end{array}$ & $\begin{array}{l}\text { - General discussion } \\
\text { - Group work } \\
\text { - Role play }\end{array}$ & Promote assertiveness and respect for others \\
\hline 8 & The new guy! & $\begin{array}{l}\text { - Role play } \\
\text { - Game } \\
\text { - General discussion of the } \\
\text { class }\end{array}$ & $\begin{array}{l}\text { Recognition and appreciation of positive qualities, acceptance of positive } \\
\text { feedback, practice and reflection on how to get to know new people }\end{array}$ \\
\hline 9 & Drugs_educate yourself & $\begin{array}{l}\text { - Group work } \\
\text { - Question and answer } \\
\text { game }\end{array}$ & Information on the positive and negative effects of drug use \\
\hline 10 & Coping strategies & $\begin{array}{l}\text { - Presentation } \\
\text { - General discussion } \\
\text { - Group work }\end{array}$ & Expression of negative feelings, dealing with challenges \\
\hline 11 & $\begin{array}{l}\text { Problem solving and } \\
\text { decision-making }\end{array}$ & $\begin{array}{l}\text { - Presentation } \\
\text { - General discussion } \\
\text { - Group work } \\
\text { - Homework }\end{array}$ & Problem solving and fostering creative thinking and self-control \\
\hline 12 & $\begin{array}{l}\text { Setting goals and final } \\
\text { considerations }\end{array}$ & $\begin{array}{l}\text { - Game } \\
\text { - Group work } \\
\text { - General discussion }\end{array}$ & $\begin{array}{l}\text { Distinguish the long-term and short-term goals, evaluate the program and its } \\
\text { process }\end{array}$ \\
\hline
\end{tabular}

in this protocol, we describe a study that will be carried out in the years 2019 and 2020 to evaluate the revised version of the \#Tamojunto program [16], now called \#Tamojunto 2.0.

The teachers who will administer the program will be trained in a 16-h training program conducted by professionals from the $\mathrm{BMH}$. In addition, the implementation will be accompanied by two on-site visits by BMH professionals throughout the 12 lessons and by a virtual forum where teachers can post questions about the application of the activities in the lessons.

\section{Data analysis of the randomized controlled trial}

The data will initially be analyzed by a descriptive analysis, that is, qualitative variables will be summarized as numbers and percentages and numerical variables as means, standard deviations, medians, minima and maxima. Descriptive analyses will be performed for different patterns of drug use. This dataset will be used to calculate sample weights through the svy command in Stata so that the baseline data analysis can be presented in an expanded form, aiming at correcting for losses and extrapolating the data to the sample universe $[39,40]$.

All analyses will be carried out in the two samples: "intention to treat" (ITT), which will include all the participating classes that received at least one lesson of the program, and "per protocol" (PP). The PP analysis will include only those classes that receive the complete protocol (12 lessons), determined based on evaluating 
the dose and fidelity form that will be completed by the teacher at the end of each lesson.

Because the data are collected in groups, they are not independent at two levels (school and class), and the measures of association should be analyzed through GLLAMM (Generalized Linear Latent and Mixed Models), which calculates the level of dependence between the data [41]. Due to the hierarchical structure of the data, multilevel models will be used to simultaneously test for differences in the prevalence of outcomes between times and between groups, considering schools as a modeling level (Gllamm Stata 14). All analyses will be adjusted by sex, socioeconomic level and site. The analyses will be performed in Stata 15 (descriptive analyses and multilevel GLLAMM), and a significance level of $5 \%$ will be adopted.

Structural equation modeling (SEM) will be used to analyze the mediators involved in reducing the primary and secondary outcomes over 18 months [42] (Fig. 2) and to assess the effectiveness of the intervention in changing the behavioral patterns of adolescents related to drug use and violence through latent transition analysis (LTA). LTA can be understood as a longitudinal extension of latent class analysis, as it is used to identify and describe the ideal number of classes representing the study population, following their transition over a given period [43]. This approach offers great advantages compared to traditional logistic regression methods in longitudinal studies, such as a lower rate of false discovery compared to multilevel logistic regression models when assessing the effects of an intervention on multiple outcomes [44]. Drug use is often studied with the latent class model due to the high correlation observed between the different drugs used, addressing the heterogeneity of drug use behavior in adolescents [45]. These analyses will be performed with the Mplus 8 software, and a significance level of $5 \%$ will be adopted.

\section{Dose and Fidelity evaluation data analysis}

Quantitative data will be analyzed using the Stata 14 software using descriptive statistics, considering frequencies and prevalence. Inferential statistics will be applied to test hypotheses of differences between observations and observers.

The qualitative data will be transcribed in full and categorized according to their content similarity. The computer software NVivo version 10 will be used for the qualitative analysis [46].

\section{Trial status}

By the time of this submission (February/2019), the study is in the recruitment and agreement phase with the selected schools.

\section{Discussion}

This study protocol describes a randomized controlled trial to evaluate the effectiveness of the school-based drug prevention program \#Tamojunto 2.0. The main objective of this study is to evaluate the effectiveness of the intervention in terms of drug use outcomes among Brazilian students. Data on school violence, psychiatric symptoms, and mediators of the program's effectiveness, such as decision-making skills, refusal skills and knowledge and beliefs about drugs, will also be collected.

\section{Strengths and limitations}

One of the strengths of this study is that it will include a representative sample of students from Brazilian public schools $(n=6300)$, obtained through a simple random draw of schools from the universe of schools in each municipality. In addition, this study will have three data collection points over time and can thus assess possible short-term and long-term effects of the program and enable more sophisticated analyses, such as mediation analysis and latent class transition analysis. Third, the study will use a school randomization design, which minimizes the effects of contamination that can occur in a project

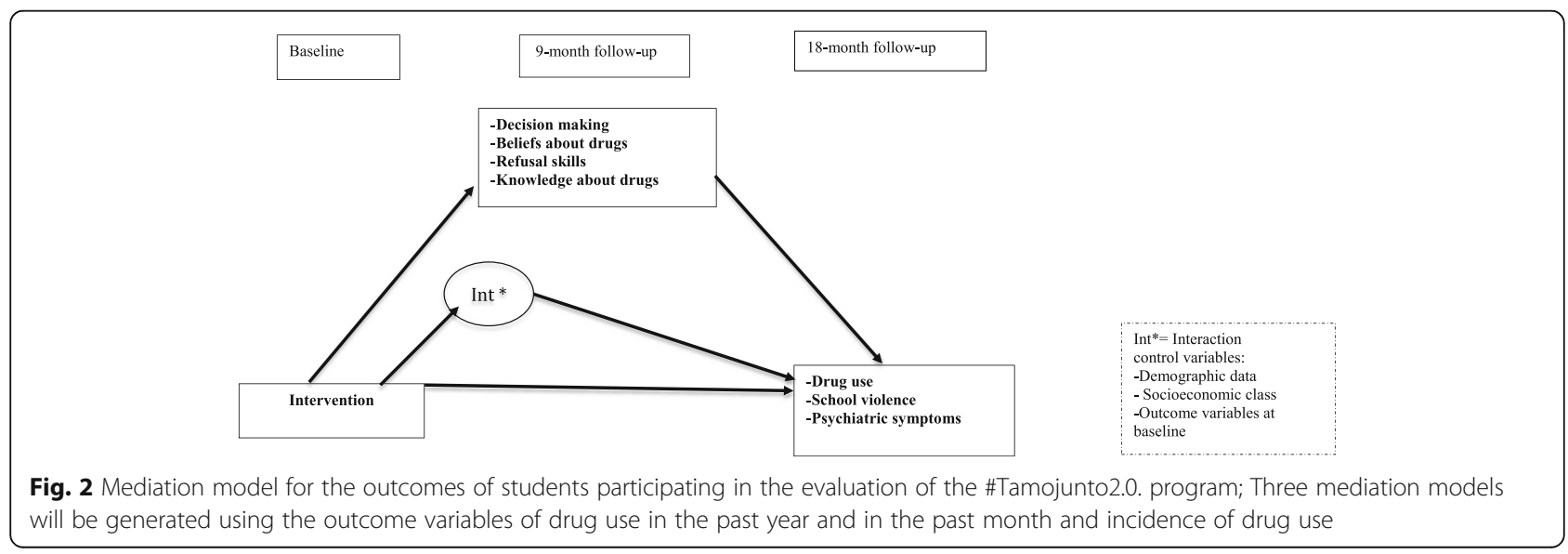


that randomizes the classes within each school. An additional strength of the study is that-in contrast to most RCT studies-we will focus not only on the effectiveness of the program but also on the mediators of change, which will shed light on how the intervention works and enable the proposal of possible mechanisms of action, as has already occurred in a pilot manner by the research group itself [16].

To contribute to the understanding of the intervention results, the present study will examine whether the intervention was implemented according to the original plan and the dose received in each participating class through the use of a dose and fidelity evaluation. The dose received in the implementation and the fidelity (i.e., how closely the program follows the original curriculum) are elements related to the expected outcomes of the program [47]. In this way, the study will identify the real conditions of the program implementation in the Brazilian public education system. Given the results obtained by Sanchez et al. [16], showing that the first version of the adaptation of the Unplugged program in Brazil resulted in a $30 \%$ increase in alcohol initiation by students, and considering the important changes made to the material to reverse this effect, it is important to evaluate whether 1) removing the components with a possible iatrogenic effect from the alcohol lesson was truly effective and 2) whether the lessons are being taught exactly as described in the handbooks provided to the teachers and students.

Some limitations of this study must be noted. The main limitation is related to the known high rate of school absences of the Brazilian student population, which could result in bias. However, this is a common limitation to longitudinal studies [48-50], and the goal is to try to minimize it by giving prior notice to the students about the researchers' visit for data collection, which did not occur in previous versions of the study [16]. Another limitation of the study is that the information is obtained through selfreporting by the students themselves. Although this method may lead to measurement bias, self-reporting is the most recommended evaluation method for adolescents and has been found to have excellent validity in studies evaluating drug-related behaviors [51, 52]. Currently, there are no viable alternatives for collecting data on alcohol use in adolescent samples, as biological measures would not be appropriate in a sample in the early stages of alcohol use [53]. To avoid the overreporting of drug use, a question of the use of fictitious drugs (holoten and carpinol) has been added to the questionnaire to screen this problem. In cases where the student responds positively to these drugs, the questionnaire will be excluded from the study, reducing the information bias [54].

\section{Conclusion}

Considering the iatrogenic results of the first version of \#Tamojunto, a new adaptation of the material was carried out to better reflect the original content of Unplugged, which has already shown positive preventive results in the European context. Thus, a randomized controlled trial protocol with the inclusion of implementation dose and fidelity measures was designed to evaluate the effectiveness of the new version of the program that will be applied by the Brazilian government, now titled \#Tamojunto 2.0. Considering that the \#Tamojunto 2.0. program was developed with the aim of being applied as a universal intervention, within a context of a national public policy, we believe that this study will contribute to supporting decision-making regarding the dissemination of the new version of this program in Brazilian public schools.

\section{Abbreviations}

ABEP: Brazilian Market Research Association; BMH: Brazilian Ministry of Health: EU-DAP: European Drug Addiction Prevention Trial; GLLAMM: Generalized Linear Latent and Mixed Models; INEP: National Institute for Educational Studies and Research 'Anísio Teixeira'; ITT: Intention To Treat; LTA: Latent Transition Analysis; PP: Per Protocol; RCT: randomized controlled trial; SEM: Structural equation modeling; UNODC: United Nations Office on Drugs and Crime

\section{Acknowledgments \\ We acknowledge past and present workers at the Ministry of Health, that believe and invest in prevention.}

\section{Authors' contributions}

The submitted manuscript has been read and approved by all authors. All authors acknowledge that they have exercised due care in ensuring the integrity of the work. ZMS designed the study, wrote the grant protocol and was responsible for the final approval of the version to be published; JYV and APDF were responsible for drafting the article and literature review; HCM performed the sample size calculation and the randomization of the schools; MHSM was responsible for writing the fidelity evaluation; SCC and $J \mathrm{JM}$ were critical reviewers of the study design, instrument and the present manuscript.

\section{Funding}

This study is part of the Center for Research and Innovation in Prevention of Mental Disorders and Drug Use (CEPIPREV - Centro para Pesquisas e Inovações em Prevenção de Transtornos Mentais e Uso de Álcool e Outras Drogas) in the Federal University of São Paulo, funded by the Brazilian Ministry of Health. This study was funded by the Brazilian Ministry of Health through TED number 176-2017, responsible for financial support and implementation of the intervention. The evaluation (study design; collection, management, analysis, and interpretation of data; writing of the report; and the decision to submit the report for publication) will be performed by an independent team from the university, will no interference of the funder.

\section{Availability of data and materials} Not applicable.

\section{Ethics approval and consent to participate}

The protocol was approved by the Ethics Committee of the Federal University of São Paulo (protocol \#2806301) and the Ethics Committee of the Municipal Health Secretariat (protocol \#3099865). Consent to participate in the study will be obtained from the schools' directors, the students and the parents. All students will take part voluntarily after having given their free and informed consent based on the autonomy of adolescents guaranteed by the Brazilian Statute of the Child and Adolescent (Law No. 8069/1990). Moreover, parents will receive a writing informed consent of the study from 
the directors of Sao Paulo schools and can recommend non-participation in data collection if they prefer. However, participation in the intervention is part of the school curriculum and is mandatory for all the students in the participating schools.

\section{Consent for publication}

No applicable.

\section{Competing interests}

Zila M Sanchez is a member of the editorial board of this journal. The other authors have no competing interests.

\section{Author details}

'Department of Preventive Medicine, Universidade Federal de São Paulo, Rua Botucatu, 740, São Paulo 04023-062, Brazil. ²Department of Psychiatry, Universidade Federal de São Paulo, Rua Major Maragliano, 241, São Paulo 04017-030, Brazil. ${ }^{3}$ Department of Clinical Psychology, Universidade Federal de São Paulo, Av. Professor Melo Moraes, 1721, São Paulo 05508-030، Brazil.

\section{Received: 10 April 2019 Accepted: 31 May 2019}

\section{Published online: 13 June 2019}

\section{References}

1. Whiteford HA, Degenhardt L, Rehm J, Baxter AJ, Ferrari AJ, Erskine HE, et al. Global burden of disease attributable to mental and substance use disorders: findings from the global burden of disease study 2010. Lancet. 2013;382:1575-86. https://doi.org/10.1016/S0140-6736(13)61611-6.

2. Lopes GM, Nobrega BA, Del Prette G, Scivoletto S. Use of psychoactive substances by adolescents: current panorama. Rev Bras Psiquiatr. 2013; 35(suppl 1):S51-61. https://doi.org/10.1590/1516-4446-2013-S105.

3. Meier MH, Caspi A, Ambler A, Harrington H, Houts R, Keefe RSE, et al. Persistent cannabis users show neuropsychological decline from childhood to midlife. Proc Natl Acad Sci. 2012;109:E2657-64. https://doi.org/10.1073/ pnas.1206820109.

4. James A, James C, Thwaites T. The brain effects of cannabis in healthy adolescents and in adolescents with schizophrenia: a systematic review. Psychiatry Res. 2013;214:181-9. https://doi.org/10.1016/j.pscychresns.2013.07. 012.

5. IBGE. Pesquisa Nacional de Saúde do Escolar 2015. Rio de Janeiro: IBGE, Coordenação de População e Indicadores Sociais; 2016.

6. NIDA. Preventing Drug Use among Children and Adolescents, 2nd Ed. 2003. 6-17. https://www.drugabuse.gov/sites/default/files/preventingdruguse_2_1. pdf. Accessed 1 Jan 2017.

7. Sloboda Z, Bukoski WJ. Handbook of Drug abuse prevention: Springer US 2006

8. Foxcroft DR, Tsertsvadze A. Universal multi-component prevention programs for alcohol misuse in young people. In: Foxcroft DR, editor. Cochrane Database of Systematic Reviews. Chichester, UK: John Wiley \& Sons, Ltd; 2011. doi:https://doi.org/10.1002/14651858.CD009307.

9. Strøm H, Adolfsen F, Fossum S, Kaiser S, Martinussen M. Effectiveness of school-based preventive interventions on adolescent alcohol use: a metaanalysis of randomized controlled trials. Subst Abuse Treat Prev Policy. 2014; 9:48. https://doi.org/10.1186/1747-597X-9-48.

10. Cuijpers $P$. Effective ingredients of school-based drug prevention programs. Addict Behav. 2002;27:1009-23. https://doi.org/10.1016/S03064603(02)00295-2

11. Griffin KW, Botvin GJ. Evidence-based interventions for Preventing substance use disorders in adolescents. Child Adolesc Psychiatr Clin N Am. 2010;19:505-26. https://doi.org/10.1016/j.chc.2010.03.005.

12. Pedroso RT, Abreu S, Kinoshita RT. Aprendizagens da intersetorialidade entre saúde e educação na prevenção do uso de álcool e outras drogas. Textura. 2015;33:9-24 http://www.periodicos.ulbra.br/index.php/txra/article/view/ 1339.

13. Vadrucci S, Vigna-Taglianti FD, van der Kreeft $P$, Vassara M, Scatigna M, Faggiano F, et al. The theoretical model of the school-based prevention programme unplugged. Glob Health Promot. 2016;23:49-58. https://doi.org/ 10.1177/1757975915579800.

14. Faggiano F, Galanti MR, Bohrn K, Burkhart G, Vigna-Taglianti F, Cuomo L, et al. The effectiveness of a school-based substance abuse prevention program: EU-dap cluster randomised controlled trial. Prev Med (Baltim). 2008;47:537-43. https://doi.org/10.1016/j.ypmed.2008.06.018.
15. Gabrhelik R, Duncan A, Miovsky M, Furr-Holden CDM, Stastna L, Jurystova L. "Unplugged": a school-based randomized control trial to prevent and reduce adolescent substance use in the Czech Republic. Drug Alcohol Depend. 2012:124:79-87.

16. Sanchez ZM, Valente JY, Sanudo A, Pereira APD, Cruz JI, Schneider D, et al The \#Tamojunto Drug prevention program in Brazilian schools: a randomized controlled trial. Prev Sci. 2017;18:772-82. https://doi.org/10. 1007/s11121-017-0770-8

17. Sanchez ZM, Valente JY, Sanudo A, Pereira APD, Schneider DR, Andreoni S. Effectiveness evaluation of the school-based drug prevention program \#Tamojunto in Brazil: 21-month follow-up of a randomized controlled trial. Int J Drug Policy. 2018;60(August 2017):10-7. https://doi.org/10.1016/j. drugpo.2018.07.006.

18. Madruga CS, Quirino C. Programas de Prevenção implantados pelo Ministério da Saúde: Considerações quanto ao potencial de expansão. In: Prevenção ao Uso de Drogas no Brasil. Brasília: Ministério da Saúde Universidade Federal de São Paulo; 2018. p. 223-67.

19. Cox E, Leung R, Baksheev G, Day A, Toumbourou JW, Miller P, et al. Violence prevention and intervention Programmes for adolescents in Australia: a systematic review. Aust Psychol. 2016;51:206-22. https://doi.org/10.1111/ap.12168.

20. Hahn R, Fuqua-Whitley D, Wethington H, Lowy J, Crosby A, Fullilove M, et al. Effectiveness of universal school-based programs to prevent violent and aggressive behavior. Am J Prev Med. 2007;33:S114-29. https://doi.org/ 10.1016/j.amepre.2007.04.012.

21. Botvin GJ, Griffin KW, Nichols TD. Preventing youth violence and delinquency through a universal school-based prevention approach. Prev Sci. 2006;7:403-8. https://doi.org/10.1007/s11121-006-0057-y.

22. Chan A-W, Tetzlaff JM, Altman DG, Laupacis A, Gøtzsche PC, Krleža-Jerić K, et al. SPIRIT 2013 statement: defining standard protocol items for clinical trials. Ann Intern Med. 2013;158:200. https://doi.org/10.7326/0003-4819-1583-201302050-00583

23. Schulz KF, Altman DG, Moher D. CONSORT 2010 statement: updated guidelines for reporting parallel group randomised trials. J Clin Epidemiol. 2010;63:834-40. https://doi.org/10.1016/j.jclinepi.2010.02.005.

24. DONNER A, KLAR N. Design and analysis of cluster randomization trials in Health Research. London: Arnold; 2000.

25. Sanchez ZM, Sanudo A, Andreoni S, Schneider D, Pereira APD, Faggiano F. Efficacy evaluation of the school program unplugged for drug use prevention among Brazilian adolescents. BMC Public Health. 2016;16:1206 https://doi.org/10.1186/s12889-016-3877-0.

26. Faggiano F, Vigna-Taglianti F, Burkhart G, Bohrn K, Cuomo L, Gregori D, et al. The effectiveness of a school-based substance abuse prevention program: 18-month follow-up of the EU-dap cluster randomized controlled trial. Drug Alcohol Depend. 2010;108:56-64. https://doi.org/10.1016/j. drugalcdep.2009.11.018

27. Cainelli de Oliveira Prado M, Schneider DR, Sañudo A, Pereira APD, Horr JF, Sanchez ZM. Transcultural adaptation of questionnaire to evaluate Drug use among students: the use of the EU-dap European questionnaire in Brazil. Subst Use Misuse. 2016;51:449-58. https://doi.org/10.3109/10826084.2015. 1117108.

28. Carlini EL de A, Noto AR, Sanchez Z van der M, Carlini CM de A, Locatelli $D P$, Abeid LR, et al. VI Levantamento nacional sobre o consumo de drogas psicotrópicas entre estudantes do ensino fundamental e médio das redes pública e privada de ensino nas 27 capitais brasileiras. Brasília: SENAD Secretaria Nacional de Políticas sobre Drogas; 2010.

29. Medeiros PFP, Cruz JI, Schneider DR, Sanudo A, Sanchez ZM. Process evaluation of the implementation of the unplugged program for drug use prevention in Brazilian schools. Subst Abuse Treat Prev Policy. 2016;11(1). https://doi.org/10.1186/s13011-015-0047-9.

30. Solberg ME, Olweus D. Prevalence estimation of school bullying with the Olweus bully/victim questionnaire. Aggress Behav. 2003;29:239-68. https:// doi.org/10.1002/ab.10047.

31. Goodman R. The strengths and difficulties questionnaire: a research note. J Child Psychol Psychiatry. 1997;38:581-6. https://doi.org/10.1111/j.1469-7610. 1997.tb01545.x.

32. Fidalgo TM, Sanchez ZM, Caetano SC, Maia LO, Carlini EA, Martins SS. The association of psychiatric symptomatology with patterns of alcohol, tobacco, and marijuana use among Brazilian high school students. Am J Addict. 2016;25:416-25. https://doi.org/10.1111/ajad.12407.

33. Garcia FD, Grigioni S, Chelali S, Meyrignac G, Thibaut F, Dechelotte P. Validation of the French version of SCOFF questionnaire for screening of 
eating disorders among adults. World J Biol Psychiatry. 2010;11:888-93. https://doi.org/10.3109/15622975.2010.483251.

34. Giannotta F, Vigna-Taglianti F, Rosaria Galanti M, Scatigna M, Faggiano F. Short-term mediating factors of a school-based intervention to prevent youth substance use in Europe. J Adolesc Health. 2014;54:565-73. https:// doi.org/10.1016/j.jadohealth.2013.10.009.

35. Brazilian Market Research Association. Changes in the application of the Brazilian criteria in force as of January 1 st ,. 2015. http://www.abep.org/ Servicos/Download.aspx?id=11\&p=en.

36. Galanti MR, Siliquini R, Cuomo L, Melero JC, Panella M, Faggiano F. Testing anonymous link procedures for follow-up of adolescents in a school-based trial: the EU-DAP pilot study. Prev Med (Baltim). 2007;44:174-7.

37. Levenshtein V. Binary codes capable of correcting deletions, insertions and reversals. Dokl Akad Nauk SSSR. 1965;163:845-8.

38. Van Der KP, Wiborg G, Galanti MR, Siliquini R, Bohrn K, Scatigna M, et al. 'Unplugged': a new European school programme against substance abuse. Drugs Educ Prev Policy. 2009;16:167-81. https://doi.org/10.1080/ 09687630701731189.

39. Carlini-Cotrim B, Barbosa M. Pesquisas Epidemiológicas sobre o Uso de Drogas entre Estudantes: Um Manual de Orientaçōes Gerais. São Paulo: CEBRID - Centro Brasileiro de Informaçōes sobre Drogas Psicotrópicas, Departamento de Psicobiologia, Escola Paulista de. Medicina. 1993.

40. Jones S, Sutton B, Boyle K. Survey methodology for studying substance use prevention programs in schools. In: Chaubey YP, editor. Recent advances in statistical methods. London: World Scientific; 2002. p. 157-68.

41. Rabe-hesketh S, Skrondal A, Pickles A. Berkeley GLAMM Manual. University of California, U.C. Berkeley division of BiostatisticsWorking Paper Series 2004;:1160. http://biostat.jhsph.edu/ fdominic/teaching/bio656/software/gllamm. manual.pdf. Accessed 23 Jun 2017.

42. MacKinnon DP, Fairchild AJ, Fritz MS. Mediation analysis. Annu Rev Psychol. 2007;58:593-614. https://doi.org/10.1146/annurev.psych.58.110405.085542.

43. Lanza ST, Patrick ME, Maggs JL. Latent transition analysis: benefits of a latent variable approach to modeling transitions in substance use. J Drug Issues. 2010;40:93-120.

44. Nylund KL. Latent transition analysis: modeling extensions and an application to peer victimization: University of California Los Angeles; 2007.

45. Evans-Polce R, Lanza S, Maggs J. Heterogeneity of alcohol, tobacco, and other substance use behaviors in U.S. college students: a latent class analysis. Addict Behav. 2016;53:80-5. https://doi.org/10.1016/j.addbeh.2015. 10.010 .

46. Gibbs GR. Qualitative data analysis: explorations with NVivo. New York: Open University Press; 2007.

47. Dusenbury L, Brannigan R, Falco M, Hansen WB. A review of research on fidelity of implementation : implications for drug abuse prevention in school settings. Heal Educ Res Theory Pract Pages. 2003;18:237-56.

48. Ariza C, Pérez A, Sánchez-Martínez F, Diéguez M, Espelt A, Pasarín MI, et al. Evaluation of the effectiveness of a school-based cannabis prevention program. Drug Alcohol Depend. 2013;132:257-64. https://doi.org/10.1016/j. drugalcdep.2013.02.012.

49. Newton NC, Teesson M, Vogl LE, Andrews G. Internet-based prevention for alcohol and cannabis use: final results of the climate schools course Addiction. 2010;105:749-59.

50. Shope JT, Dielman TE, Butchart AT, Campanelli PC, Kloska DD. An elementary school-based alcohol misuse prevention program: a follow-up evaluation. Stud Alcohol. 1992;53:106-21. https://doi.org/10.15288/jsa.1992.53.106.

51. Clark DB, Winters KC. Measuring risks and outcomes in substance use disorders prevention research. J Consult Clin Psychol. 2002;70:1207-23.

52. Crowley TJ, Mikulich SK, Ehlers KM, Whitmore EA, Macdonald MJ. Validity of structured clinical evaluations in adolescents with conduct and substance problems. J Am Acad Child Adolesc Psychiatry. 2001;40:265-73. https://doi. org/10.1097/00004583-200103000-00005.

53. Carroll KM, Carroll KM. Methodological issues and problems in the assessment of substance use. Psychol Assess. 1995;7:349-58

54. Sanderson S, Tatt ID, Higgins JPT. Tools for assessing quality and susceptibility to bias in observational studies in epidemiology: a systematic review and annotated bibliography. Int J Epidemiol. 2007;36:666-76. https:// doi.org/10.1093/ije/dym018.

\section{Publisher's Note}

Springer Nature remains neutral with regard to jurisdictional claims in published maps and institutional affiliations.

\section{Ready to submit your research? Choose BMC and benefit from}

- fast, convenient online submission

- thorough peer review by experienced researchers in your field

- rapid publication on acceptance

- support for research data, including large and complex data types

- gold Open Access which fosters wider collaboration and increased citations

- maximum visibility for your research: over $100 \mathrm{M}$ website views per year

At BMC, research is always in progress.

Learn more biomedcentral.com/submissions 